\title{
Cathepsin B as a marker of the dedifferentiated chondrocyte phenotype*
}

\author{
ANTONIO BAICI, ANGELA LANG, DOROTHY HÖRLER, \\ AND MARGRIT KNÖPFEL
}

From the Department of Rheumatology, University Hospital of Zurich, Zurich, Switzerland.

SUMMARY Rabbit articular cartilage does not secrete cathepsin B in organ culture. By

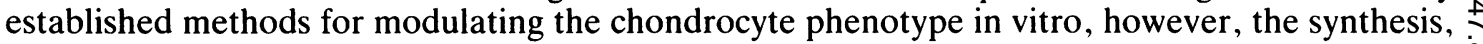
intracellular storage, and secretion of cathepsin B were followed up over a period of two months. $\stackrel{\infty}{\infty}^{\circ}$ With chondrocytes grown in monolayer cultures both the intracellular pool of the enzyme and its $\stackrel{\infty}{\oplus}$ secretion were very small initially, but increased progressively to a factor of 110 after eight weeks. 을 The secretion of cathepsin B was strongly depressed after transferring the cells from monolayer to collagen gel cultures. In contrast, collagenase was secreted in almost the same amounts during the whole period in both monolayer and collagen gel cultures. The cells cultured in collagen gels secreted more collagenase than those grown in monolayers. The reversible switch of cathepsin B secretion suggests that this enzyme, unlike collagenase, is a marker of the dedifferentiated $\vec{\emptyset}$

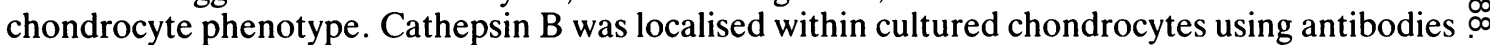
raised against rabbit liver cathepsin $B$ and shared with it many catalytic properties. Its $M_{r}$, however, was higher (34000 compared with 27000 ) and showed an unusual resistance to denaturation at neutral-alkaline $\mathrm{pH}$, which may confer on this enzyme an important role in the degradation of cartilage matrix.

Key words: collagenase, cysteine endopeptidases, rabbit, articular chondrocytes, cell cultures immunolocalisation.

The biochemical response of the chondrocyte in osteoarthritis is characterised by two apparently contrasting factors: repair and remodelling, on the one hand, and destruction of connective tissue, on the other. In osteoarthritis the ability of the chondrocytes to synthesise the cartilage specific type II collagen is greatly diminished or lost. Instead they efficiently produce fibrocartilaginous material comprising collagen fibres derived from type I collagen. ${ }^{12}$ This anomalous behaviour is interpreted as a loss of the highly specialised differentiated phenotype of the chondrocyte. ${ }^{3}$

Chondrocyte mediated breakdown of cartilage has been the subject of numerous studies. ${ }^{4}$ The discovery of the existence of synovial factors (e.g., interleukin 1) has greatly stimulated research in this

\footnotetext{
Accepted for publication 30 January 1988.

Correspondence to Dr Antonio Baici. Department of Rheumatology, Biochemical Laboratory, University Hospital, CH-8091 Zurich, Switzerland.

${ }^{*}$ Dedicated to Professor Giorgio Semenza in occasion of his 60th birthday.
}

field, and it is now generally accepted that these factors may promote cartilage degradation by stimulating the chondrocytes to synthesise and secrete collagenase and metal dependent proteoglycanases. ${ }^{5-7}$

Destruction of articular cartilage by endogenous hydrolases has received considerable attention after 0 the demonstration that cartilage can autodegrade. ${ }^{89}$ 을 The studies of Ali et al suggested that cathepsins $\frac{D}{0}$ acting at acidic $\mathrm{pH}$, particularly cathepsin $\mathrm{B}$, were the primary factors. ${ }^{-11}$ It has been shown that $\mathcal{N}$ homogenates of human osteoarthritic cartilage con- $N$ tain higher cathepsin B activities than normal N cartilage. $^{12}$ The importance of cathepsin B in auto- $\omega$ degradation of articular cartilage has been debated as it was doubted whether the $\mathrm{pH}$ of the cartilage $\stackrel{0}{=}$ could reach the acidic optimum for the action of the enzyme. It is known that cathepsin B is quite rapidly and irreversibly inactivated after exposure at neutral ${ }^{\circ}$ or slightly alkaline $\mathrm{pH} \cdot{ }^{13}$ This partly explains why $\overrightarrow{\mathbb{D}}$ cathepsin B from articular chondrocytes and its $\frac{O}{\mathbb{D}}$ possible involvment in cartilage breakdown have not $\stackrel{2}{2}$ been the subject of detailed study. It has recently 
been shown, however, that cathepsin B can survive in the extracellular space for a sufficiently long time to produce significant degradation of connective tissue components. ${ }^{14} 15$

In the present study some properties of collagenase and cathepsin B derived from dedifferentiated chondrocytes are described which are produced as a response to environmental rather than to chemical stimulation. Using known techniques to induce reversibly articular chondrocytes to lose and regain their characteristic phenotype, we show that cathep$\sin B$ is an enzyme produced in conspicuous amounts by dedifferentiated chondrocytes, whereas collagenase is not.

\section{Materials and methods}

TISSUE AND CELL CULTURES

Cell culture materials were obtained from Grand Island Biological Co, Basle, Switzerland. All cultures described below were performed in Dulbecco's modified Eagle's medium (DMEM) supplemented with $10 \%$ fetal calf serum, which was omitted when endopeptidases were measured, in a humidified incubator at $37^{\circ} \mathrm{C}$ and an atmosphere consisting of $95 \%$ air and $5 \% \mathrm{CO}_{2}$. For all experiments the pooled hip, knee, and shoulder cartilage of 8-10 week old New Zealand rabbits was used. Slices of articular cartilage and specimens of rabbit subcutaneous tissue were maintained in organ culture as described previously. ${ }^{16}$ Primary monolayer cultures of chondrocytes were obtained by sequential enzymatic digestion of finely minced cartilagenamely, by incubating the cartilage with $0.25 \%$ trypsin for 30 minutes at $37^{\circ} \mathrm{C}$ (the supernatant from this treatment was discarded) and then for 30 minutes with $0.2 \%$ bacterial collagenase in DMEM without serum. The collagenase treatment was repeated twice more, and the supernatants were pooled and centrifuged for 10 minutes at $800 \mathrm{~g}$. The pellet was washed twice with DMEM containing $10 \%$ fetal calf serum. Rabbit skin fibroblasts were prepared as described earlier. ${ }^{15}$ The cells were subcultured after trypsinisation of confluent monolayers according to standard procedures. Collagen gel cultures were performed according to Kimura $e t$ $a l^{17}$ with the following minor modifications. Soluble calf skin collagen (Worthington Biochemical Corp, Freehold, NJ, USA), supplied at a concentration of about $8.5 \mathrm{mg} / \mathrm{ml}$, was first dialysed against water, then shortly (20 minutes) against Hanks's balanced salt solution (HBSS), and sterilised for one hour under ultraviolet radiation. The desired concentration was obtained by dilution with DMEM. Enough collagen solution was added drop-wise with gentle shaking to a cell suspension to give final concentra- tions of $2 \times 10^{5}$ chondrocytes $/ \mathrm{ml}$ and $0.135 \%(\mathrm{w} / \mathrm{v})$ collagen. Portions of $0.50 \mathrm{ml}$ of the suspension were pipetted into 24 well plates and left to polymerise at $37^{\circ} \mathrm{C}$ for one to two hours. The polymerised pellets were then transferred to $35 \mathrm{~mm}$ dishes and covered with $2.0 \mathrm{ml}$ of medium.

SECRETION AND ANALYSIS OF CATHEPSIN B Monolayer cultures of rabbit articular chondrocytes were set up in 24 well culture plates $(16 \mathrm{~mm}$ diameter) with $1 \times 10^{5}$ cells/well in $2.0 \mathrm{ml}$ medium supplemented with $10 \%$ fetal calf serum. At the times shown in Fig. 1 the cells were washed three times with HBSS, the medium was replaced with the omission of serum, and the cells incubated for 48 hours. The media were then collected, centrifuged

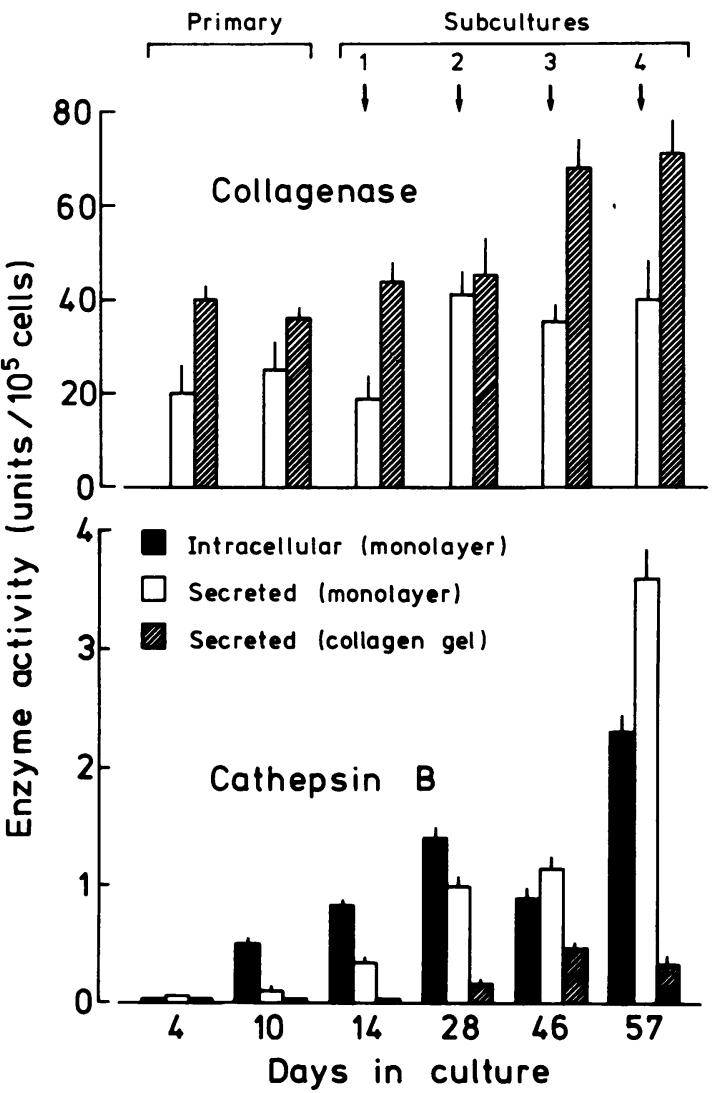

Fig. 1 Collagenase and cathepsin B produced by cultured rabbit articular chondrocytes. The hatched columns represent enzyme activities secreted by cells cultured in monolayers for the periods shown, transferred to collagen cultures, left to adhere to the collagen matrix overnight, and further cultured by this technique for 48 hours. The columns represent mean values of five to seven different culture preparations and bars indicate one $S D$. 
at $800 \mathrm{~g}$ for 10 minutes, and stored frozen at $-20^{\circ} \mathrm{C}$ until further use. In parallel, at the times shown in Fig. 1, cells grown in monolayers were collected by trypsinisation, washed, and suspended in collagen as described above. After polymerisation of the gels the cells $\left(1 \times 10^{5}\right.$ cells/gel in $2.0 \mathrm{ml}$ medium containing $10 \%$ fetal calf serum) were incubated overnight (14-18 hours) and then the pellets were washed three times with HBSS and replaced with serum free medium. After 48 hours the media were collected, centrifuged as above, and stored at $-20^{\circ} \mathrm{C}$. To measure the intracellular pool of enzyme activity the cells were quantitatively removed from the 24 well monolayer cultures by gentle sonication in a bath sonicator. The cells were then completely disrupted with a needle sonicator (Labsonic 2000 sonifier, Braun, Melsungen, FRG) operating at $50 \mathrm{~W}$ for 30 seconds. The homogenates were centrifuged at $30000 \mathrm{~g}$ for 30 minutes and the clear supernatants stored at $-20^{\circ} \mathrm{C}$ until use.

Collagenase activity was assayed by the fluorescein labelled reconstituted collagen fibril method, ${ }^{18}$ as detailed previously, ${ }^{16}$ in the presence of $1 \mathrm{mM} p$ aminophenylmercuric acetate to activate the latent enzyme. The activities were expressed as total collagenase, i.e., latent plus active, and the unit was defined as the amount of enzyme (totally inhibited by edetic acid) capable of lysing $1 \mu \mathrm{g}$ of reconstituted collagen fibrils in 16 hours under the specified conditions. Cathepsin B was assayed with $N$-carbobenzoxy-L-arginyl-L-arginine-7-(4-methyl)coumarylamide (Bachem Ltd, Bubendorf, Switzerland) as the substrate in $0 \cdot 1 \mathrm{M} \mathrm{Na}^{+} / \mathrm{K}^{+}$phosphate buffer containing $2 \mathrm{mM}$ edetic acid and $2 \mathrm{mM}$ dithiothreitol at $\mathrm{pH} 6.00$ by the general procedure detailed previously. ${ }^{16}$ One unit of activity was defined as the amount of enzyme which hydrolyses 1 nmol of substrate in six hours under the specified conditions. ${ }^{16}$

Statistical comparison of the results was performed with the non-parametric Kruskal-Wallis test and Dunn's non-parametric multiple comparison test using the computer program described by Blaker. ${ }^{19}$

MOLECULAR SIZE OF CHONDROCYTIC

CATHEPSIN B

When a confluent layer of well attached cells in serum containing medium was formed, chondrocytes from the fourth subculture were washed three times with $\mathrm{HBSS}$ (without $\mathrm{Ca}^{++}$and $\mathrm{Mg}^{++}$) and then serum free medium was added. The media from 10 culture flasks $\left(75 \mathrm{~cm}^{2}\right)$ were collected after 96 hours, pooled (about $95 \mathrm{ml}$ ), centrifuged for 30 minutes at $10000 \mathrm{~g}$, and filtered through $0.22 \mu \mathrm{m}$ membrane filters. The pool was then dialysed against doubly distilled water, lyophilised, and the lyophilisate redissolved in $4.0 \mathrm{ml}$ of $0.1 \mathrm{M} \mathrm{Na}+\mathrm{K}^{+*}$ phosphate buffer, $2 \mathrm{mM}$ edetic acid, $\mathrm{pH} 6 \cdot 00$. A small portion of this solution was applied to ac Sephadex G-75 column, which was equilibrated and흘 eluted with the same phosphate buffer as above. $\frac{\bar{\rho}}{\bar{\sigma}}$ Other portions were treated with pepsin or incu $\frac{\widehat{D}}{\Omega}$ bated at $\mathrm{pH} 3.0$ and then chromatographed on Sephadex G-75 as detailed previously. ${ }^{1520}$

IMMUNOCYTOCHEMISTRY AND

CYTOCHEM ISTRY

Cathepsin B was purified from rabbit liver, and anti bodies against this enzyme were raised in a sheep. ${ }^{2 !}$ Cathepsin B was immunolocalised in cultured cells using the sensitive avidin-biotin-peroxidase com-io plex method. ${ }^{22}$ Enzyme cytochemistry, i.e., the localisation of cathepsin B activity within cells, waso performed with $N$-carbobenzoxy-L-alanyl-L-arginyl-L-arginine-4-methoxy- $\beta$-naphthylamide (Z-Ala-Arg- $\rightarrow$ Arg-4M $\beta$ NA, Bachem Ltd, Bubendorf, Switzerland $\$ \bar{\varnothing}$ as substrate, and the reaction product was coupleds to 5-nitrosalicylaldehyde, which could be observedin the fluorescence microscope. ${ }^{2324}$ Photomicro $\infty$ graphs were taken with a Zeiss Universal microscope

\section{Results}

CELL CULTURES AND ENZYME ANALYSIS

Rabbit articular chondrocytes were established in primary monolayer cultures, allowed to proliferate $\overrightarrow{\overrightarrow{0}}$ and subcultured. Periodically, cells from monolayer cultures were transferred to collagen gels. Cathepsin $B$ and collagenase were measured in supernatants of both monolayer and collagen gel cultures after incubation for 48 hours in serum free medium. The intracellular content of cathepsin B from monolaye $\underline{B}$. cultures was measured in supernatants of celh homogenates. Fig. 1 summarises the enzyme activi ties. Collagenase was not found intracellularly in chondrocytes during the whole period of 57 days The secretion of collagenase in monolayer culture was quite uniform from the very beginning. The moderate increase at days 28,46 , and 57 was not significantly different from the value at day $4 \mathrm{~N}$ Slightly higher levels of collagenase (with respect tô the corresponding values in monolayer cultures ${ }_{b}^{\omega}$ were measured in the supernatants of cells transferred to collagen gels. The apparent increase if activity at days 46 and 57 was, however, no@ significantly different from the activity at day 4 .

In contrast with collagenase, cathepsin B showed a remarkable dependency upon the 'age' of the cells in culture and on the culture conditions. The enzyme was present intracellularly in very low amounts in primary chondrocytes at day 4 , but itse 

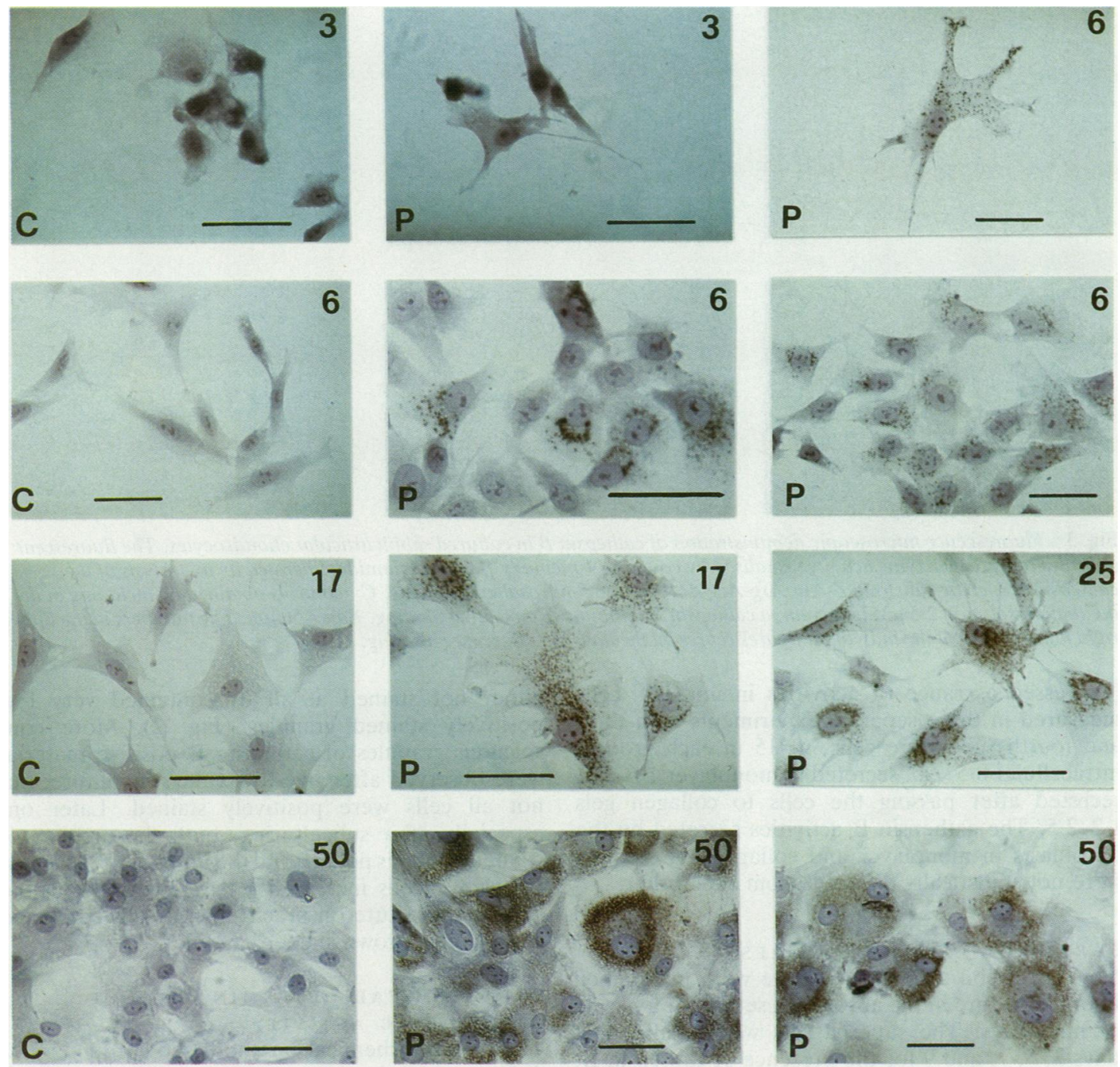

Fig. 2 Immunolocalisation of cathepsin B in cultured rabbil articular chondrocytes. Staining was performed with sheep antibodies against rabbit liver cathepsin B using the avidin-biotin-peroxidase complex method. $C=$ controls obtained with chromatographically purified non-immune sheep $\operatorname{Ig} G ; P=$ positive staining with anticathepsin $B$ antibodies. The numbers in the upper right hand corner of the individual figures represent the days in culture (see also Fig. 1). Bars $=50 \mu m$.

concentration increased progressively and significantly after some days in monolayer culture and even more after subculturing. The secreted enzyme followed a similar pattern: very low levels of activity at the beginning, which progressively increased. At day 57 the activity had increased by a factor of 110 with respect to day 4 . The secretion of cathepsin $B$, however, was depressed after transferring the cells to collagen gels. All cathepsin B activities secreted in collagen gel cultures were significantly lower $(p<0 \cdot 001)$ than the corresponding activities in monolayers from day 14 to 57 . To ascertain that the lower activities were not an artefact of the collagen gel technique rabbit skin fibroblasts were cultured in parallel with the chondrocytes and treated in the same way. It was not possible to determine accurately the cathepsin $B$ activities of the fibroblasts in primary cultures because of the difficulty of obtaining a homogeneous cell population from the very beginning. But after the third subculture the fibroblasts consisted of a homogeneous cell population and gave the following results as regards cathepsin $B$ 

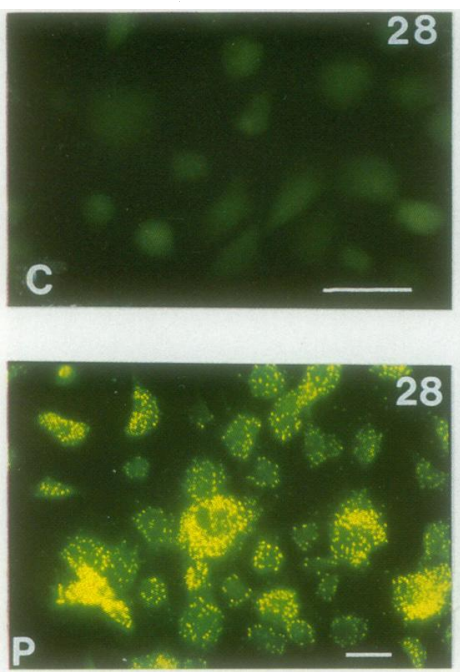
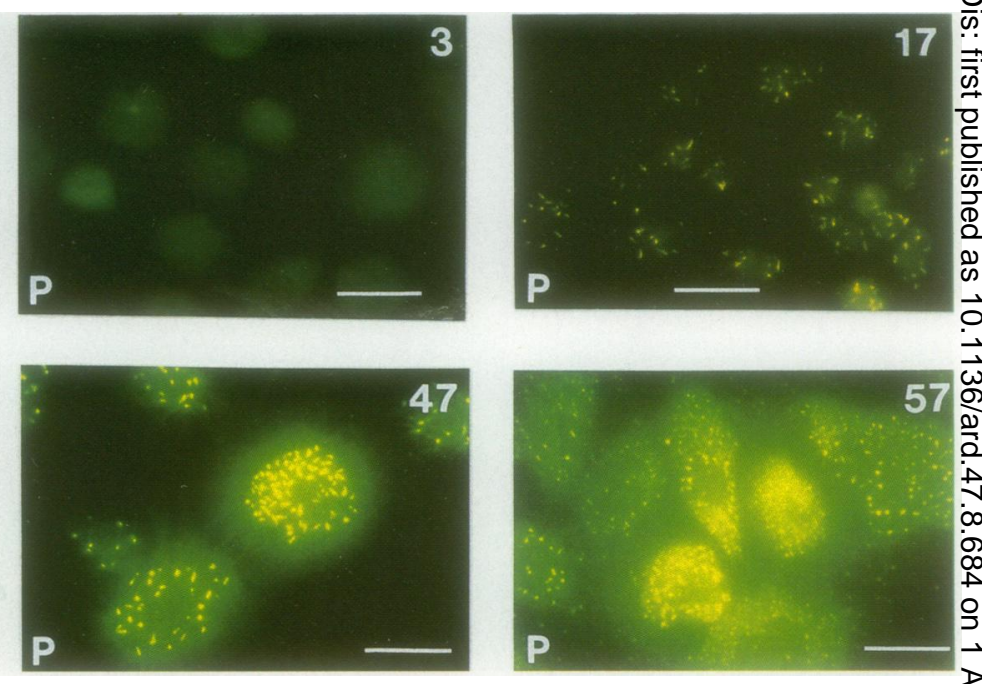

غ્ granules represent enzyme activity visualised by coupling 4-methoxy- $\beta$-naphthylamide, liberated by hydrolysis of the cathepsin B specific substrate Z-Ala-Arg-Arg-4MBNA, to 5-nitrosalicylaldehyde. C=controls obtained by including in the incubation solution $2 \cdot 5 \mu M$ leupeptin, a cathepsin B inhibitor. $P=$ positive staining. Bars $=50 \mu m$. The numbers in the upper right hand corner of the individual figures represent the days in culture (see also Fig. 1).

(expressed as range of activities in units $/ 10^{5}$ cells measured in three separate experiments with third and fourth subculture cells, $n=15$ in each group): intracellular $0 \cdot 5-2 \cdot 0$, secreted in monolayer $1 \cdot 6-2 \cdot 2$, secreted after passing the cells to collagen gels $1 \cdot 2-2 \cdot 5$. The cathepsin $B$ activities secreted by the fibroblasts in monolayer and collagen gel cultures were not statistically different from each other.

\section{CARTILAGE ORGAN CULTURES}

Slices of rabbit articular cartilage were maintained in organ culture in the absence of serum for a period of nine days. The supernatants were analysed at days $3,5,7$, and 9 for the presence of cathepsin B. None of the samples investigated contained this enzyme. As a control, specimens of rabbit subcutaneous tissue were cultured under the same conditions. Cathepsin B was regularly secreted by these cultures as has been shown and discussed elsewhere. ${ }^{15} 16$

IMMUNOCHEMICAL LOCALISATION OF

CATHEPSIN B IN CHONDROCYTES

Cathepsin B was localised in monolayer cultured chondrocytes at approximately the same intervals shown in Fig. 1. For this purpose monospecific antibodies raised against rabbit liver cathepsin B were used together with the very sensitive avidinbiotin-peroxidase complex method. Primary chondrocytes at the beginning of the culture period were either not stained at all or contained very few positively stained granules (Fig. 2). More con spicuous granules of cathepsin $\mathrm{B}$ positive materiaf

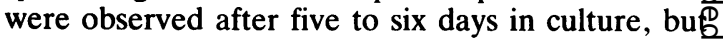
not all cells were positively stained. Later on $\overrightarrow{\vec{F}}$ especially after subculturing, both the number of stained granules per cell and the number of cathepsing B positive cells increased progressively. From the second subculture on practically all cells contained conspicuous brown stained granules.

CYTOCHEMICAL DETERMINATION OF

CATHEPSIN B ACTIVITY

The immunochemical method shown in Fig. 2 demonstrated the existence of cathepsin B in chon음 drocytes as a protein. A further confirmation of the presence of this enzyme was obtained by a․ fluorogenic intracellular activity staining techniques specific for cathepsin B, which is shown in Fig. $3 \%$ Freshly established chondrocytes in primary cultures contained very few fluorescent granules or now activity at all. Most of the cells remained negative for up to several days in primary culture. With timeo both the number of fluorescent granules per cell and the number of positively stained cells increased, in ${ }^{\text {? }}$ agreement with both the immunochemical results in Fig. 2 and with the biochemical results in Fig. 1.

For technical reasons it was not possible to localise cathepsin B in chondrocytes embedded in collagen gels either by immunochemical or cytochemical techniques. 
PARTIAL CHARACTERISATION OF CATHEPSIN B FROM CULTURED RABBIT CHONDROCYTES

Supernatants from rabbit articular chondrocytes maintained in monolayer culture (fourth subculture) were processed as detailed in 'Materials and methods' and used for determining the molecular size of cathepsin B by gel chromatography on Sephadex G-75. The secreted form of cathepsin B consisted of a major peak with an apparent $M_{r}$ of 34000 . This peak did not change its position in the chromatogram after treatment with pepsin or after prolonged incubation at $\mathrm{pH} 3 \cdot 0$. The chromatographic profiles are not shown here because the single peak detected was identical to that found earlier in supernatants of rabbit skin fibroblasts and

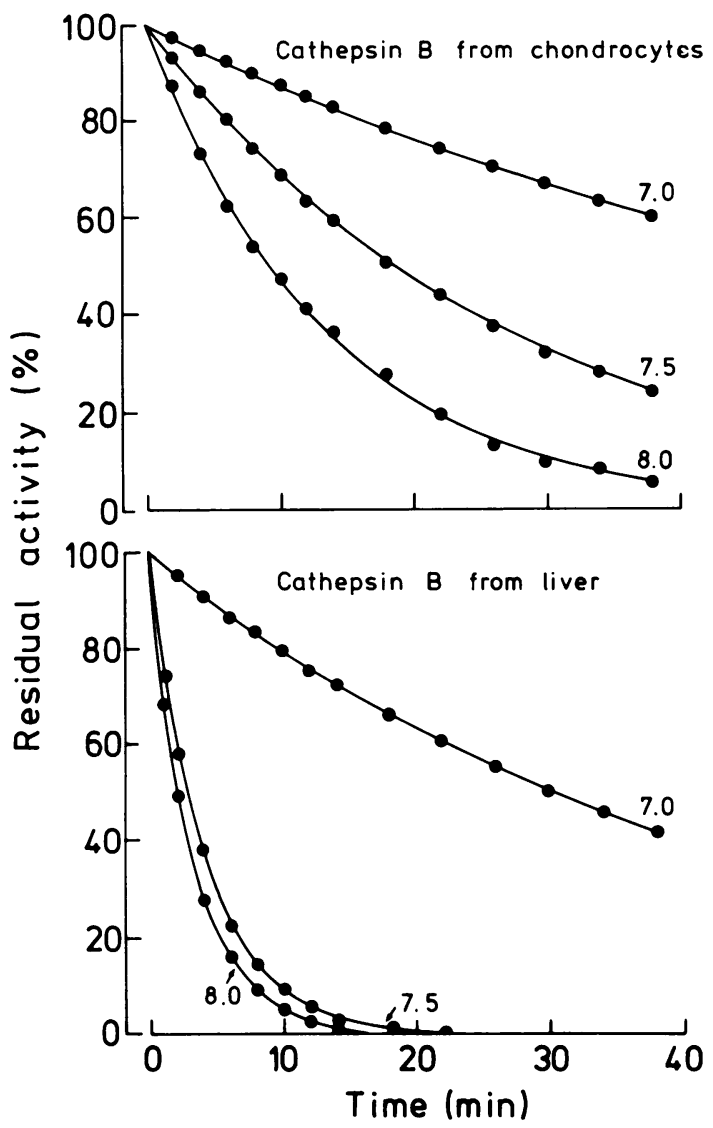

Fig. 4 pH induced inactivation of cathepsin $B$ from rabbit liver and cultured rabbit articular chondrocytes. The buffer system used was $0 \cdot 1 \mathrm{M} \mathrm{Na} / \mathrm{K}^{+}$phosphate containing $2 \mathrm{mM}$ edetic acid and $2 \mathrm{mM}$ dithiothreitol at the three $\mathrm{pH}$ values indicated (numbers labelling the curves). The data are shown as a first derivative plot obtained from progress curves. Points are experimental and the curves represent best fit values to a first order equation. ${ }^{15}$ rabbit V2 carcinoma cells (see Fig. 1, peak C in Ref. 15). Fractions from the Sephadex G-75 chromatographic separation containing cathepsin B activity corresponding to $\mathrm{M}_{\mathrm{r}}=34000$ were pooled, concentrated, and used for characterising the substrate and inhibitor specificity as detailed previously. ${ }^{15}$ The cysteine proteinases cathepsin $\mathrm{H}$ and $\mathrm{L}$ were absent, and the sensitivity to specific inhibitors confirmed that the chondrocytic enzyme was cathepsin B (results not shown, see Table III in Ref. 15).

The $\mathrm{pH}$ stability of the secreted form of cathepsin B from rabbit articular chondrocytes was measured between pH 6.0 and 8.0 at $37^{\circ} \mathrm{C}$ and compared with that of purified rabbit liver cathepsin $\mathrm{B}$. At $\mathrm{pH} 6 \cdot 0$ and 6.5 the enzyme was stable for several days. At $\mathrm{pH}$ values between $7 \cdot 0$ and $8 \cdot 0$ the activity loss was characterised by a first order reaction law, confirming previous results. ${ }^{15}$ Fig. 4 shows that the chondrocytic enzyme can resist $\mathrm{pH}$ induced irreversible denaturation much better than the liver enzyme. The half lives for enzyme activities (in minutes), calculated from semilogarithmic plots of these data, were: $50.9,18.5$, and 9.2 (chondrocytic enzyme), $30 \cdot 1,2 \cdot 8$, and $2 \cdot 2$ (liver enzyme), at $\mathrm{pH} 7 \cdot 0,7 \cdot 5$, and $8 \cdot 0$ respectively.

\section{Discussion}

Modulation of the chondrocyte phenotype in vitro can be accomplished under a variety of experimental conditions reviewed by Benya and Brown, ${ }^{3}$ and the most frequently studied aspect has been the loss of the specialised differentiated state of these cells, or 'dedifferentiation'. A typical marker of the differentiated chondrocyte phenotype is type II collagen, and a reliable indicator of dedifferentiation is the replacement of type II collagen by type $\mathrm{I} .{ }^{3} \mathrm{~A}$ widely used technique to produce dedifferentiated chondrocytes in vitro consists in cultivating them in monolayers. ${ }^{25-28}$ In contrast, 'three dimensional' cell culture techniques, such as liquid suspension, agarose, or collagen gel cultures, have been employed with success with the aim of maintaining the differentiated phenotype. ${ }^{3172930}$ These three dimensional techniques can also be used for reexpressing the differentiated chondrocyte phenotype of dedifferentiated cells grown in monolayers. ${ }^{3}$ We have used this approach to study the expression of cathepsin B and collagenase in rabbit articular chondrocytes.

Cathepsin B was not found in supernatants of slices of articular cartilage maintained in organ culture. This suggests that chondrocytes in their natural environment do not normally secrete this enzyme. This does not exclude the fact that at least some chondrocytes may contain small amounts of 
cathepsin B as part of their intracellular enzymatic equipment. ${ }^{12}$ When articular chondrocytes were freshly isolated from the surrounding matrix and placed in monolayer cultures they secreted extremely small amounts of cathepsin B, and the intracellular pool of the enzyme was also minimal. After some days in primary culture the chondrocytes began to synthesise and store intracellularly significant amounts of cathepsin B, and this effect became more apparent after serial subculture. Enzyme secretion could be reversibly switched to low levels, however, by transferring the chondrocytes from monolayers to collagen gel suspensions. The switch was surprisingly fast and was not due to an artefact of the culture conditions as rabbit skin fibroblasts, used as a control, secreted cathepsin B equally well in monolayers and in collagen gel cultures.

Collagenase did not display the same dependence upon the culture conditions. This enzyme was secreted in higher amounts when the cells were grown in collagen gel cultures instead of in monolayers, and it was more or less equally secreted from freshly isolated chondrocytes or from cells subcultured four times and maintained in culture for about two months.

The immunochemical and enzyme activity cytochemical measurements confirmed the biochemical findings just discussed. Although few chondrocytes contained sparse intracellular granules positive for cathepsin B, most of the cells, just after isolation from articular cartilage, did not contain storage granules for this enzyme. With the progression of the culture time, immunoreactive cathepsin $B$ and activity staining positive granules increased in number within a cell and more cells became positive. After the second subculture almost all cells contained conspicuous granules of cathepsin B positive material. The few cathepsin B positive cells found at the beginning of the culture period clearly show that the chondrocyte population investigated was heterogeneous. This result agrees with a previous finding by Bayliss and Ali in homogenates of human articular cartilage, where cathepsin B showed a zonal variation through the depth of cartilage. ${ }^{12}$ In particular, the surface cells appeared to contain more enzyme than those close to the subchondral bone. The interpretation was that the flat fibrocyte-type chondrocytes found near the surface of articular cartilage may be responsible for the cathepsin B activity measured.

In previous papers we characterised cathepsin $B$ in the rabbit V2 carcinoma-rabbit fibroblasts system. ${ }^{15} 162021$ As regards the fibroblasts, cathepsin B was secreted as a precursor with an apparent $M_{r}$ of 43000 , which could be converted after limited proteolysis with pepsin or by prolonged incubation at $\mathrm{pH} 3.0$ to a form having $\mathrm{M}_{\mathrm{r}}=34000$ and a increased specific activity. Normally, cathepsin B is. stored intracellularly in a variety of cells with an $\mathrm{M}$ ? around 27000 . Recently, these various moleculas forms of cathepsin B have also been characterised i human fibroblasts. ${ }^{31}$ Cultured rabbit articular chon ${ }^{5}$ drocytes secreted only the cathepsin B form wit $M_{r}=34000$, which displayed the same substrate specificity and sensitivity to inhibitors as lysosomal cathepsin $\mathrm{B}$, thus reflecting the properties of the enzyme from rabbit skin fibroblasts. ${ }^{15}$ Besides the higher molecular mass, the other major difference of the chondrocytic enzyme with respect to lysoso 0 mal cathepsin B is its unusual stability at $\mathrm{pH}$ values above 7. Owing to their stability at neutral-alkaline $\mathrm{pH}$, high molecular mass forms of cysteine endopepos tidases have been implicated as possible mediators of tissue destruction in tumour invasion. ${ }^{15}{ }^{32-38}$ The high $M_{r}$ forms of cysteine endopeptidases in several tumour-host systems have been interpreted as ent zyme precursors. These can be released in the extracellular space as a consequence of a rate of biosynthesis which is too high to allow efficient post translational modifications of the proteins and theifo subsequent storage in lysosomes as mature enzymes. ${ }^{32}$ As regards dedifferentiated chondroe cytes, it is conceivable that these cells synthesise excessive amounts of a cathepsin B precursor, whic can be processed and stored intracellularly only i part, whereas a considerable portion of the enzyme precursor is released outside of the cell.

Chondrocytes may be stimulated to secrete cartiF age degrading enzymes under the influence of cytokines. ${ }^{6}$ One of these enzymes, collagenase, is. produced in excess by chrondocytes stimulated witte cytokines. ${ }^{39}$ Dedifferentiated chondrocytes do nof seem to follow the same mechanism as norma chondrocytes secrete even more collagenase thain the dedifferentiated counterpart (see above), an the opposite is true for cathepsin B.

There is a major conceptual difference between the above discussed phenomena related to tumous invasion and the cytokine induced release of cartie age degrading enzymes by articular chondrocyteş, on the one hand, and the secretion of enzymes bou dedifferentiated chondrocytes, on the othen Whereas in the former case the cells are stimulated by a chemical signal, in the second case the stimulation is represented by a change of the environmental conditions, which can induce the chondrocytes to undergo morphological and biochemical transformation. It has been proposed that the cytoskeleton is involved in this kind of transe formation with a reversible change of the cell shape from spherical to spread. Cytoskeletal reorganisation may be responsible for the transduction of shape 
information into interpretable signals for gene expression. ${ }^{3}$

In conclusion, cathepsin B, unlike collagenase, can be considered as a further marker of the dedifferentiated chondrocyte phenotype. The resistance to denaturation at neutral-alkaline $\mathrm{pH}$ may confer on this enzyme an important role in the degradation of cartilage matrix. Although a relation between our in vitro results and the situation found in vivo in osteoarthritic cartilage must still be demonstrated, the study by Bayliss and Ali, ${ }^{12}$ which showed increased cathepsin B activities in human osteoarthritic cartilages, may represent the biological counterpart of our in vitro study.

We thank the 'Stiftung für Rheumaforschung', Zurich for a generous grant towards this project. We also gratefully acknowledge the encouragement by Professors A Böni. K Fehr, and F J Wagenhäuser.

\section{References}

1 Gay S. Müller P K. Lemmen C. Remberger K. Matzen K. Kühn K. Immunohistological study on collagen in cartilagebone metamorphosis and degenerative osteoarthrosis. Klin Wochenschr 1976: 54: 969-76.

2 Nimni M E. Deshmukh K. Differences in collagen metabolism between normal and osteoarthritic human cartilage. Science 1973; 181: 752-3.

3 Benya P D. Brown P D. Modulation of the chondrocyte phenotype in vitro. In: Kuettner K E. Schleyerbach R. Hascall $\checkmark$ C. eds. Articular cartilage biochemistry. New York: Raven Press. 1986: 219-33.

4 Ehrlich M G. Armstrong A L. Treadwell B V. Mankin H J. Degradative enzyme systems in cartilage. Clin Orthop 1986; 213: $62-8$.

5 Saklatvala J. Interleukin 1: purification and biochemical aspects of its action on cartilage. J Rheumatol 1987: 14 (suppl 14): 52-4

6 Jasin H E. Dingle J T. Human mononuclear cell factors mediate cartilage matrix degradation through chondrocyte activation. J Clin Invest 1981: 68: 571-81.

7 Hamerman D. Klagsbrun M. Osteoarthritis. Emerging evidence for cell interactions in the breakdown and remodelling of cartilage. Am J Med 1985; 78: 495-9.

8 Lucy J A. Dingle J T. Fell H B. Studies on the mode of action of excess vitamin A. II. A possible role of intracellular proteases in the degradation of cartilage matrix. Biochem J 1961; 79: 500-8.

9 Ali S Y. The degradation of cartilage matrix by an intracellular protease. Biochem J 1964: 93: 611-8.

10 Ali S Y. The presence of cathepsin B in cartilage. Biochem J 1967: 102: 10-11c

11 Ali S Y. Evans L. Stainthorpe E. Lack C H. Characterization of cathepsins in cartilage. Biochem $J$ 1967; 105: 549-57.

12 Bayliss M T. Ali S Y. Studies on cathepsin B in human articular cartilage. Biochem J 1978: 171: 144-54.

13 Barrett A J. Human cathepsin B1. Purification and some properties of the enzyme. Biochem $J$ 1973: 131: 809-22.

14 Mort J S. Recklies A D. Poole A R. Extracellular presence of the lysosomal proteinase cathepsin B in rheumatoid synovium and its activity at neutral pH. Arthritis Rheum 1984; 27 : 509-15.

15 Baici A. Knöpfel M. Cysteine proteinases produced by cultured rabbit V2 carcinoma cells and rabbit skin fibroblasts. Int J Cancer 1986; 38: 753-61.

16 Baici A. Gyger-Marazzi M. Sträuli P. Extracellular cysteine proteinase and collagenase activities as a consequence of tumorhost interaction in the rabbit V2 carcinoma. Invasion Metastasis 1984: 4: 13-27.
17 Kimura T. Yasui N. Ohsawa S. Ono K. Chondrocytes embedded in collagen gels maintain cartilage phenotype during long-term cultures. Clin Orthop 1984: 186: 231-9.

18 Baici A. Cohen G. Fehr K. Böni A. A handy assay for collagenase using reconstituted fluorescein-labeled collagen fibrils. Anal Biochem 1980: 108: 230-2.

19 Blaker W D. Computer program for the parametric and nonparametric comparison of several groups to a control. Comput Biol Med 1987: 17: 37-44.

20 Baici A, Knöpfel M, Keist R. Tumor-host interactions in the rabbit V2 carcinoma. Stimulation of cathepsin B in host fibroblasts by a tumor-derived cytokine. Invasion Metastasis 1988; 8: 143-58.

21 Graf M. Baici A. Sträuli P. Histochemical localization of cathepsin $B$ at the invasion front of the rabbit V2 carcinoma. Lab Invest 1981; 45: 587-96.

22 Graf F M. Sträuli P. Use of the avidin-biotin-peroxidase complex $(\mathrm{ABC})$ method for the localization of rabbit cathepsin $\mathrm{B}$ in cells and tissues. J Histochem Cvtochem 1983: 31: 803-10.

23 Graf M. Lecmann U. Ruch F. Sträuli P. The fluoresence and bright field microscopic demonstration of cathepsin $B$ in human fibroblasts. Histochemistry 1979: 64: 319-22.

24 Dolbeare F. Vanderlaan M. A fluorescent assay of proteinases in cultured mammalian cells. J Histochem Cytochem 1979: 27: 1493-5.

25 Coon H G. Clonal stability and phenotypic expression of chick cartilage cells in vitro. Proc Natl Acad Sci USA 1966; 55: 66-73.

26 Holtzer H. Abbott J. Lash J. Holtzer S. The loss of phenotypic traits by differentiated cells in vitro. I. Dedifferentiation of cartilage cells. Proc Natl Acad Sci USA 1960; 46: 1533-42.

27 Layman D L. Sokoloff L. Miller E J. Collagen synthesis by articular chondrocytes in monolayer culture. Exp Cell Res 1972; 73: $107-12$.

28 Mayne R, Vail M S. Mayne P M. Miller E J. Changes in type of collagen synthesized as clones of chick chondrocytes grow and eventually lose division capacity. Proc Natl Acad Sic USA 1976; 73: $1674-8$.

29 Horwitz A L. Dorfman A. The growth of cartilage cells in soft agar and liquid suspension. J Cell Biol 1970; 45: 434-8.

30 Nevo Z, Dorfman A. Stimulation of chondromucoprotein synthesis in chondrocytes by extracellular chondromucoprotein. Proc Natl Acad Sci USA 1972: 69: 2069-72.

31 Hanewinkel H. Glössl J. Kresse H. Biosynthesis of cathepsin B in cultured normal and I-cell fibroblasts. J Biol Chem 1987; 262: 12351-5.

32 Mort J S, Recklies A D. Interrelationship of active and latent secreted human cathepsin B precursors. Biochem J 1986; 233: $57-63$.

33 Sloane B F. Honn K V. Cysteine proteinases and metastasis. Cancer Metastasis Rev 1984: 3: 249-63.

34 Recklies A D. Mort J S. Poolc A R. Secretion of a thiol proteinase from mouse mammary carcinomas and its characterization. Cancer Res 1982; 42: 1026-32.

35 Recklies A D. Poole A R. Mort J S. A cysteine proteinase secreted from human breast tumors is immunologically related to cathepsin B. Biochem J 1982: 207: 633-6.

36 Mort J S. Leduc M S. Recklies A D. Characterization of a latent cystcine proteinase from ascitic fluid as a high molecular weight form of cathepsin B. Biochim Biophys Acta 1983; 755: 369-75.

37 Mort J S. Leduc M. Recklies A D. A latent thiol proteinase from ascitic fluid of patients with neoplasia. Biochim Biophys Acta 1981: 662: 173-80.

38 Mort J S. Recklies A D. Poole A R. Characterization of a thiol proteinase secreted by malignant human breast tumors. Biochim Biophys Acta 1980: 614: 134-43.

39 Evêquoz V. Schnyder J. Trechsel U. Baggiolini M. Fleisch H. Influence of macrophage products on the release of plasminogen activator, collagenasc. $\beta$-glucuronidase and prostaglandin E2 by articular chondrocytes. Biochem J 1984: 219: 667-7. 